OPEN ACCESS

Quantifying the Distribution of Electrolyte Decomposition Products in Silicon-Graphite Electrodes by Neutron Depth Profiling

To cite this article: Morten Wetjen et al 2018 J. Electrochem. Soc. 165 A2340

View the article online for updates and enhancements. 


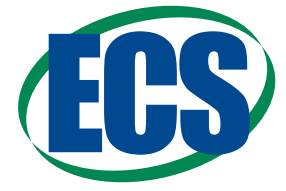

\title{
Quantifying the Distribution of Electrolyte Decomposition Products in Silicon-Graphite Electrodes by Neutron Depth Profiling
}

\author{
Morten Wetjen, ${ }^{1,=, *, z}$ Markus Trunk, ${ }^{2}=$ Lukas Werner, ${ }^{2}$ Roman Gernhäuser, ${ }^{3}$ \\ Bastian Märkisch, ${ }^{2}$ Zsolt Révay, ${ }^{4}$ Ralph Gilles, ${ }^{4}$ and Hubert A. Gasteiger ${ }^{1, * *}$ \\ ${ }^{1}$ Chair of Technical Electrochemistry, Department of Chemistry and Catalysis Research Center, \\ Technische Universität München, D-85748 Garching, Germany \\ ${ }^{2}$ Professorship of Fundamental Particle Physics at Low Energies, Technische Universität München, \\ D-85748 Garching, Germany \\ ${ }^{3}$ Physics Department, Technische Universität München, D-85748 Garching, Germany \\ ${ }^{4}$ Heinz Maier-Leibnitz Zentrum (MLZ), Technische Universität München, D-85748 Garching, Germany
}

\begin{abstract}
Silicon-based anodes for lithium-ion batteries exhibit severe volumetric changes of the active material particles during (de-)lithiation, resulting in continuously occurring side reactions at the silicon/electrolyte interface over extended charge/discharge cycling. The thus formed and accumulating electrolyte decomposition products lead to a growth of the solid-electrolyte-interphase (SEI) on the silicon particles. This results not only in an ongoing loss of electrolyte but also in a significant swelling and impedance increase of silicon-based anodes which significantly compromises their cycle-life. In the present study, neutron depth profiling (NDP) is used post mortem as a non-destructive, highly lithium-sensitive technique to (i) quantify the amount of lithium-containing electrolyte decomposition products in silicon-graphite ( $\mathrm{SiG}$ ) electrodes ( $35 \mathrm{wt} \%$ silicon, areal capacity $\sim 1.7 \mathrm{mAh} \mathrm{cm}^{-2}$ ), (ii) monitor their distribution across the $\mathrm{SiG}$ electrode thickness, and (iii) determine the active material utilization across the electrode over 140 cycles. Hence, $\mathrm{SiG}$ negative electrodes are aged and characterized by means of galvanostatic cycling in $\mathrm{SiG} / / \mathrm{LiFePO}_{4} \mathrm{pseudo}-$ full cells, using a capacitively oversized positive electrode and an electrolyte mixture consisting of $1 \mathrm{M} \mathrm{LiPF}_{6}$ in EC:EMC with $5 \mathrm{wt} \%$ FEC. High-resolution cross-sectional SEM images and post-mortem characterization of the SiG electrodes with respect to changes in electrode mass thickness complement the analysis.

(C) The Author(s) 2018. Published by ECS. This is an open access article distributed under the terms of the Creative Commons Attribution 4.0 License (CC BY, http://creativecommons.org/licenses/by/4.0/), which permits unrestricted reuse of the work in any medium, provided the original work is properly cited. [DOI: 10.1149/2.1341810jes]

(c)) BY
\end{abstract}

Manuscript submitted June 18, 2018; revised manuscript received July 23, 2018. Published August 1, 2018. This article is a version of Paper 427 from the Cancun, Mexico, Meeting of the Society, September 30-October 4, 2018.

Silicon is among the most promising anode materials for future lithium-ion batteries to achieve cell-level energy densities above $300 \mathrm{Wh} \mathrm{kg}^{-1} \cdot{ }^{1-3}$ Yet, its commercialization is still hampered by the large morphological changes of the silicon particles upon repeated (de-)lithiation. ${ }^{4,5}$ These changes result in (i) a continuous consumption of electrolyte with a concomitant accumulation of electrolyte decomposition products in porous silicon-based electrodes, ${ }^{6-8}$ and (ii) a significant swelling of the entire electrode structure, leading to electrode polarization and a loss of reversible capacity. ${ }^{9,10}$ Numerous research groups investigated the degradation of silicon-based electrodes, e.g., using in-situ X-ray diffraction (XRD), ${ }^{11,12}$ nuclear magnetic resonance spectroscopy (NMR), ${ }^{13-16}$ X-ray photoelectron spectroscopy (XPS), ${ }^{17,18}$ and focused ion beam scanning electron microscopy (FIBSEM). ${ }^{19-21}$ These measurements provided valuable insights into the side-reactions of the silicon particles as well as the formation of electrolyte decomposition products which lead to a growth of the solidelectrolyte-interphase (SEI). ${ }^{22}$ Nonetheless, most of these methods do not provide information on the extent of electrolyte decomposition products across the thickness of the electrode which would allow further insight into the degradation mechanism of silicon-based electrodes. This can be provided by neutron depth profiling (NDP), a non-destructive and highly lithium-sensitive technique which enables a depth-resolved quantification of the lithium concentration across the electrode thickness of up to $\sim 50 \mu \mathrm{m} .{ }^{23-25}$ In 2009 , Whitney et al. ${ }^{26,27}$ used NDP for the first time to determine the SEI growth on graphite anodes at different storage conditions. Later, Co and co-workers ${ }^{28,29}$ applied NDP to measure the lithium distribution in a tin-based thinfilm alloy electrode (12.5 $\mu \mathrm{m}$ thickness), using an in-situ setup that consisted of a lithium metal anode and an electrolyte mixture of $1 \mathrm{M}$ $\mathrm{LiBF}_{4}$ in EC:DMC. More recently, Zhang et al. ${ }^{30}$ used a similar insitu setup to investigate the influence of the electrode morphology and

\footnotetext{
$=$ These authors contributed equally to this work.

*Electrochemical Society Student Member.

**Electrochemical Society Fellow.

${ }^{\mathrm{z}}$ E-mail: morten.wetjen@tum.de
}

the C-rate on the lithium gradients across a $12.5 \mu \mathrm{m}$ thick $\mathrm{LiFePO}_{4}$ cathode coating.

Here, the degradation of silicon-graphite ( $\mathrm{SiG}$ ) electrodes (35 wt\% silicon) with an areal capacity of $\sim 1.7 \mathrm{mAh} \mathrm{cm}^{-2}$ is studied post mortem by ex-situ NDP to (i) quantify the amount of lithiumcontaining electrolyte decomposition products, (ii) monitor their distribution across the electrode coatings, and (iii) determine the active material utilization across the $\mathrm{SiG}$ electrodes over the course of 140 charge/discharge cycles. SiG electrodes were aged and characterized by means of galvanostatic cycling in $\mathrm{SiG} / / \mathrm{LiFePO}$ pseudo-full cells, using a capacitively oversized positive electrode and an electrolyte mixture consisting of $1 \mathrm{M} \mathrm{LiPF}_{6}$ in EC:EMC with $5 \mathrm{wt} \%$ fluoroethylene carbonate (FEC). ${ }^{7}$ Over the course of charge/discharge cycling, side reactions occurring at the silicon/electrolyte interface result in the continuous preferential consumption of FEC which is accompanied by the accumulation of lithium-containing electrolyte decomposition products, ${ }^{6,8}$ consisting of $\mathrm{LiF}, \mathrm{Li}_{2} \mathrm{CO}_{3}, \mathrm{Li}_{2} \mathrm{O}$, and lithium alkoxides. ${ }^{18,31,32}$ After different numbers of cycles, fully delithiated $\mathrm{SiG}$ electrodes were harvested from the cells and characterized by ex-situ NDP. In this case, residual lithium in the electrodes mainly originates from the lithium poly(acrylate) (LiPAA) binder and from the lithium-containing electrolyte decomposition products, independent of their chemical state. ${ }^{7}$ The NDP analysis method was recently implemented and validated using pristine and aged $\mathrm{SiG}$ electrodes by Trunk et al. ${ }^{33}$ at the newly constructed neutron depth profiling instrument (N4DP) at the Prompt Gamma-ray Activation Analysis (PGAA) facility of the Heinz Maier-Leibnitz Zentrum (MLZ) in Garching, Germany. In the present work, these NDP results are analyzed by taking into account the electrochemical performance and the morphological changes of the $\mathrm{SiG}$ electrodes. Hence, the mass loading and the thickness increase of the electrodes were determined post-mortem and compared to the NDP measurements. In addition, high-resolution cross-sectional SEM images were taken to further elucidate the morphological changes of the SiG electrodes. The study concludes with a detailed discussion of the degradation phenomena of SiG electrodes and the influence of the electrolyte decomposition products on cycling performance. 


\section{Experimental}

Electrode preparation.-Silicon-graphite ( $\mathrm{SiG})$ electrodes, consisting of $35 \mathrm{wt} \%$ silicon nanoparticles $(\sim 200 \mathrm{~nm}$, Wacker Chemie AG, Germany), 45 wt $\%$ graphite $(\sim 20 \mu \mathrm{m}$, T311, SGL Carbon, Germany), $10 \mathrm{wt} \%$ vapor grown carbon fibers (VCGF-H, Showa Denko, Japan), and $10 \mathrm{wt} \%$ lithium poly(acrylate) binder (LiPAA) were prepared by an aqueous ink procedure, which is described in detail in our previous publication. ${ }^{7}$ The LiPAA was prepared by diluting a $35 \mathrm{wt} \%$ poly(acrylic acid) solution (PAA, MW $=250,000 \mathrm{~g} \mathrm{~mol}^{-1}$, Sigma-Aldrich, Germany) with deionized water and neutralizing it with lithium hydroxide ( $\mathrm{LiOH}$, Sigma-Aldrich, Germany) to a $\mathrm{pH}$ value of $\sim 8 .^{34}$ The mass loading of the electrodes was adjusted to $1.44 \pm 0.04 \mathrm{mg}_{\text {electrode }} \mathrm{cm}^{-2}$, which corresponds to a theoretical areal capacity of $2.05 \pm 0.06 \mathrm{mAh} \mathrm{cm}{ }^{-2}$ (referenced to theoretical specific capacities of $3579 \mathrm{mAh} \mathrm{g}^{-1} \mathrm{Si}$ and $372 \mathrm{mAh} \mathrm{g}^{-1} \mathrm{C}$ ). During the first cycle at a C-rate of $0.1 \mathrm{~h}^{-1}$, the $\mathrm{SiG}$ electrodes delivered a delithiation capacity of $1.69 \pm 0.05 \mathrm{mAh} \mathrm{cm}^{-2}$.

Test cell assembly.-Electrochemical characterization and aging of the $\mathrm{SiG}$ electrodes was conducted in coin-cells (Hohsen, Japan), by sandwiching two $250 \mu \mathrm{m}$ thick glass fiber separators (VWR, USA) between a SiG anode $\left(\sim 1.7 \mathrm{mAh} \mathrm{cm}^{-2}\right.$ at $0.1 \mathrm{~h}^{-1}, 14 \mathrm{~mm}$ diameter $)$ and a capacitively oversized $\mathrm{LiFePO}_{4}(\mathrm{LFP})$ cathode $\left(\sim 3.5 \mathrm{mAh} \mathrm{cm}^{-2}\right.$ at $0.1 \mathrm{~h}^{-1}, 15 \mathrm{~mm}$ diameter, Customcells, Germany). As electrolyte, $100 \mu \mathrm{L}$ of $1 \mathrm{M} \mathrm{LiPF}_{6}$ in ethylene carbonate:ethyl methyl carbonate (EC:EMC, 30:70 wt\%; also referred to as LP57), with $5 \mathrm{wt} \%$ fluoroethylene carbonate (FEC) was used.

Battery cycling.-The electrode polarization and cycling performance of the $\mathrm{SiG}$ electrodes was investigated by means of galvanostatic cycling of $\mathrm{SiG} / / \mathrm{LFP}$ coin-cells. As in our previous publication, ${ }^{7}$ the cell voltage was controlled between the $\mathrm{SiG}$ and the LFP electrode, whereby the $\mathrm{SiG}$ potential was calculated from the $\mathrm{SiG} / \mathrm{LFP}$ cell voltage, referring to a stable LFP electrode potential of $3.45 \mathrm{~V}$ vs. $\mathrm{Li}^{+} / \mathrm{Li}$. Initially, two formation cycles at a C-rate of 0.1 $\mathrm{h}^{-1}\left(\sim 0.2 \mathrm{~mA} \mathrm{~cm}{ }^{-2}\right)$ were performed between cell voltages of 3.44 and $2.2 \mathrm{~V}$, corresponding to $\mathrm{SiG}$ potential of $\sim 0.01$ and $\sim 1.25 \mathrm{~V}$ vs. $\mathrm{Li}^{+} / \mathrm{Li}$. For consecutive cycling, the C-rate was increased to $0.5 \mathrm{~h}^{-1}$ $\left(\sim 1.0 \mathrm{~mA} \mathrm{~cm}^{-2}\right)$, whereby the $\mathrm{C}$-rate is always referenced to the theoretical capacity of the electrodes, i.e., $1.0 \mathrm{~h}^{-1}$ equals $\sim 2.0 \mathrm{~mA} \mathrm{~cm}^{-2}$. During the last cycle of each procedure and prior to disassembly of the coin-cells, the $\mathrm{SiG}$ electrodes were again lithiated to $0.01 \mathrm{~V}$ vs. $\mathrm{Li}^{+} / \mathrm{Li}$ at $0.5 \mathrm{~h}^{-1}$ and then delithiated to $\sim 2.0 \mathrm{~V}$ vs. $\mathrm{Li}^{+} / \mathrm{Li}$ at a very low C-rate of $0.02 \mathrm{~h}^{-1}\left(\sim 0.04 \mathrm{~mA} \mathrm{~cm}^{-2}\right)$ in order to extract any residual active lithium from the $\mathrm{SiG}$ electrodes. All measurements were performed in a climate chamber (Binder, Germany) at $25^{\circ} \mathrm{C}$, using a multi-channel potentiostat VMP3 (BioLogic, France).

Test cell disassembly._Following the charge/discharge cycling and the slow delithiation in the last cycle, the SiG//LFP coin-cells were disassembled in their fully discharged state in an argon-filled glovebox $\left(\mathrm{H}_{2} \mathrm{O}\right.$ and $\mathrm{O}_{2}$ concentration $<0.1 \mathrm{ppm}$; MBraun). The $\mathrm{SiG}$ electrodes were harvested from the cells and carefully rinsed with $50 \mu \mathrm{L}$ of dimethyl carbonate (DMC) to remove any residues of the liquid electrolyte. Thus, remaining lithium in these electrodes mainly originated from the LiPAA binder and the lithium-containing electrolyte decomposition products, which can be ascribed to the irreversible capacity loss. Finally, the $\mathrm{SiG}$ electrodes were weighed and then sealed separately in pouch-foils before being opened again just before the transfer into the NDP vacuum chamber, whereby electrodes were exposed to ambient atmosphere only for a few minutes prior to NDP measurements.

Neutron depth profiling.-The NDP measurements of the SiG electrodes were conducted ex-situ using the N4DP setup at the PGAA facility of the MLZ in Garching, Germany. ${ }^{33}$ The beamline provides a collimated cold neutron beam with an area of $12.6 \mathrm{~mm}^{2}$ and a flux of $1.35 \times 10^{9} \mathrm{~cm}^{-2} \mathrm{~s}^{-1}$ which can be reduced by different attenuators
$(5.9 \%, 16 \%$, and $47 \%)$ to mitigate pile-up effects at count rates above $10^{3} \mathrm{~s}^{-1} .35$ The $14 \mathrm{~mm}$ diameter $\mathrm{SiG}$ electrodes were placed in the NDP vacuum chamber with the coating facing the incoming beam at an angle of $45^{\circ}$. The N4DP setup at the PGAA facility is described in more detail by Trunk et al. ${ }^{33}$

High-resolution cross-sectional SEM images.-The morphology of the $\mathrm{SiG}$ electrodes in their pristine state and after different numbers of cycles was investigated by high-resolution cross-sectional scanning electron microscopy (SEM). First, electrode cross-sections were prepared by argon ion beam polishing, using a JEOL Cross Section Polisher IB-19530CP (JEOL, Japan). Afterwards, SEM images were taken using a JEOL JSM-IT300HR (JEOL, Japan) with a fieldemission electron source and a secondary electron detector. Both the preparation of the electrode cross-sections and the measurements of the cross-sectional SEM images were conducted by JEOL (Germany) $\mathrm{GmbH}$ in Freising, Germany.

Quantification of electrode thickness changes.-The changes in the $\mathrm{SiG}$ electrode thickness were measured by cross-sectional scanning electron microscopy (SEM) with the aid of a JEOL JCM6000 NeoScope (JEOL, Japan), using a procedure described in detail elsewhere. ${ }^{10}$ After the NDP measurements, the SiG electrodes were cut across the center of the electrodes. One half was polished by the argon ion beam and measured by high-resolution SEM as described above. The other half was embedded into a resin solution; after hardening of the resin, the samples were polished stepwise using different polishing papers down to $1 \mu \mathrm{m}$ size to obtain a mirror finished cross-section of the electrodes. Each electrode was evaluated at fifteen positions along the entire cross-section to obtain an average thickness and its standard deviation.

\section{Results and Discussion}

Charge/discharge cycling and post-mortem characterization of SiG electrodes.-Figure 1a shows the areal delithiation capacity (brown symbols) and the total irreversible capacity (marine symbols) of the $\mathrm{SiG}$ electrode as a function of the cycle number, exemplarily shown for the cell cycled over 120 cycles (the total irreversible capacity after 120 cycles from two cells is reproducible within $\pm 5 \%$; see blue symbols at cycle 120 in Figure 4a). After two formation cycles at a C-rate of $0.1 \mathrm{~h}^{-1}$ where $\sim 83 \%$ of the theoretical capacity of $2.05 \mathrm{mAh} \mathrm{cm}^{-2}$ are obtained, the initially delivered delithiation capacity at the subsequently higher C-rate of $0.5 \mathrm{~h}^{-1}$ amounts to $\sim 1.4 \mathrm{mAh} \mathrm{cm}^{-2}$ ( $\sim 68 \%$ of the theoretical capacity). The cycling stability of the $\mathrm{SiG}$ electrodes is characterized by a distinct capacity decay to $\sim 0.9 \mathrm{mAh} \mathrm{cm}^{-2}$ within the first 60 cycles $(\sim 65 \%$ capacity retention, referenced to the $3^{\text {rd }}$ cycle at $0.5 \mathrm{~h}^{-1}$ ), perhaps more evident by the steep increase in the total irreversible capacity within the first 60 cycles (marine symbols in Figure 1a), which can be used as a measure for the accumulation of electrolyte decomposition products in the porous electrode. This behavior is also reflected by the differential capacity curves shown in Figure 1b which, within the first 60 cycles, reveal a distinct capacity fade at low degrees of lithiation, i.e., at potentials above $0.2 \mathrm{~V} \mathrm{vs.} \mathrm{Li}^{+} / \mathrm{Li}$ during lithiation (see lower left segment in Figure $1 b),{ }^{7}$ a characteristic feature observed if the delithiation during the preceding lithiation cycles is incomplete. ${ }^{36}$ In our earlier work, ${ }^{10}$ it was demonstrated that the increase in the electrode impedance and the loss of interparticle electrical contact is caused by the drastic expansion of the surface area of the silicon particles over the initial charge/discharge cycles, accompanied by an initially high formation rate of electrolyte decomposition products and high SEI growth as well as by a significant swelling of the $\mathrm{SiG}$ electrode. It is to note that although FEC is continuously reduced at the silicon/electrolyte interface, the total amount in the electrolyte solution is large enough to prevent a complete depletion and subsequent reductive decomposition of EC within the here investigated 140 cycles. ${ }^{6,8}$

Figure 2 shows (a) the mass loading and (b) the coating thickness of the SiG electrodes which were determined post-mortem after 

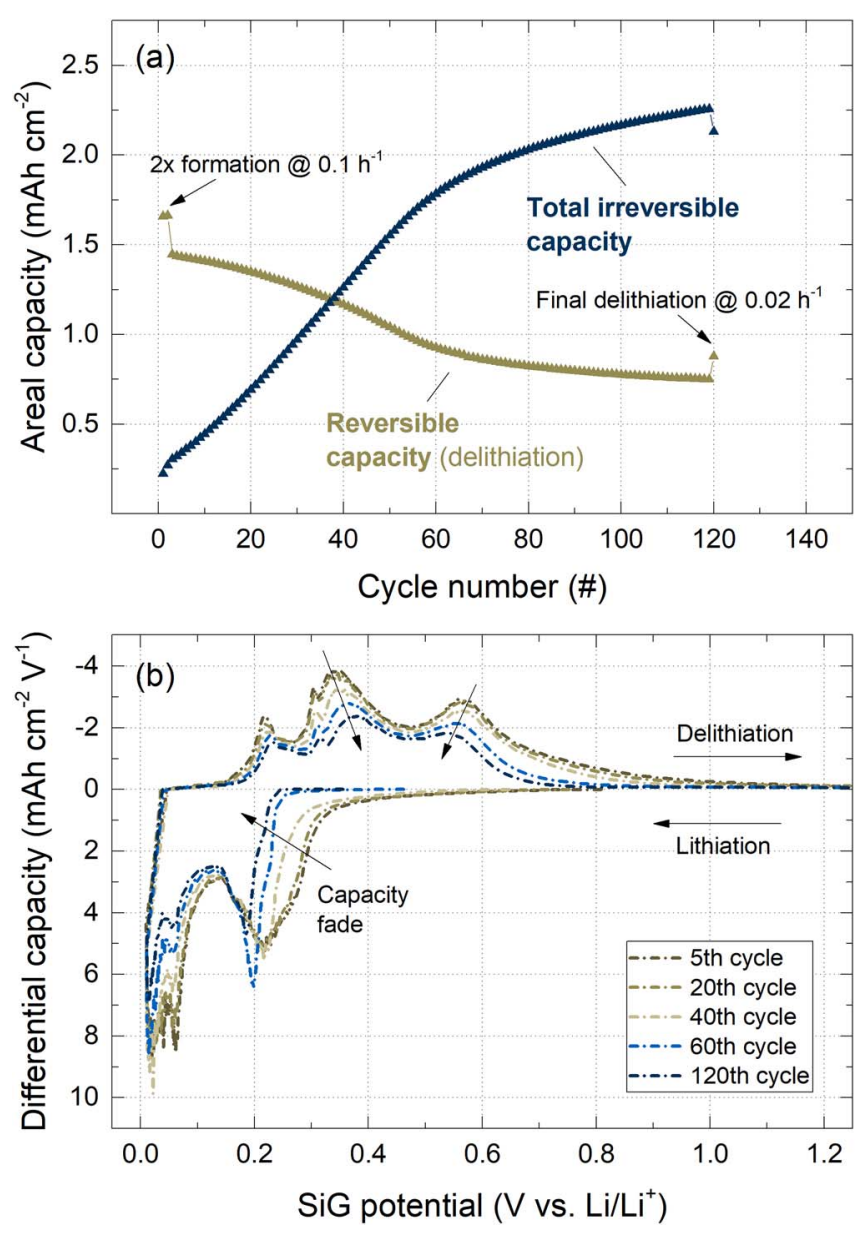

Figure 1. (a) Areal delithiation capacity (brown symbols) and total accumulated irreversible capacity (marine symbols) of a SiG electrode $(\sim 1.7 \mathrm{mAh}$ $\mathrm{cm}^{-2}$ at $0.1 \mathrm{~h}^{-1}$ ) cycled between $\mathrm{SiG}$ potentials of 0.01 and $1.25 \mathrm{~V} \mathrm{vs.} \mathrm{Li}^{+} / \mathrm{Li}$, obtained from galvanostatic cycling of $\mathrm{SiG} / / \mathrm{LFP}$ coin-cells at a C-rate of $0.5 \mathrm{~h}^{-1}$ with a capacitively oversized LFP electrode $\left(\sim 3.5 \mathrm{mAh} \mathrm{cm}^{-2}\right.$ at $0.1 \mathrm{~h}^{-1}$ ) in LP57 with $5 \mathrm{wt} \%$ FEC. (b) Differential capacity curves of selected cycles at $0.5 \mathrm{~h}^{-1}$ plotted vs. the SiG electrode potential (obtained by considering a stable $\mathrm{LFP}$ electrode potential of $3.45 \mathrm{~V} \mathrm{vs.} \mathrm{Li}^{+} / \mathrm{Li}$ ).

different numbers of cycles by weighing and by thickness measurements using cross-sectional SEM images. In (c), the electrode porosity was calculated based on the thickness and mass loading of the electrodes, using estimated average densities of $2.33 \mathrm{~g} \mathrm{~cm}^{-3}$ for silicon, $2.0 \mathrm{~g} \mathrm{~cm}^{-3}$ for graphite and the carbon fibers, $1.5 \mathrm{~g} \mathrm{~cm}^{-3}$ for the LiPAA binder, and $1.6 \pm 0.2 \mathrm{~g} \mathrm{~cm}^{-3}$ for the electrolyte decomposition products (this calculation is outlined in detail in reference ${ }^{7}$ ). Analogous to the cycling data, these electrode properties undergo a drastic change within the first 60 cycles. While the mass loading increases from $\sim 1.4$ to $\sim 3.9 \mathrm{mg} \mathrm{cm}^{-2}$, the coating swells from $\sim 19 \mu \mathrm{m}$ to $\sim 49 \mu \mathrm{m}$. In contrast, between 80 and 140 cycles, only minor changes can be observed, resulting in a final mass loading of $4.4 \mathrm{mg} \mathrm{cm}^{-2}$ and a coating thickness of $\sim 51 \mu \mathrm{m}$, respectively. The $\approx 5-10 \%$ decrease in the measured electrode thickness for the electrodes aged for 120 and 140 cycles, likely originates from a slightly lower initial mass loading and thus also a smaller coating thickness prior to cycling. Yet, it is to note that the preparation of the electrodes is quite reproducible, yielding an average thickness and standard deviation for the pristine electrodes of $18.7 \pm 0.3 \mu \mathrm{m}$.

Based on a recent TEM investigation, ${ }^{10}$ it was indeed expected that after 60 cycles the further increase of the mass loading and the coating thickness would become very small, as the cycling induced structural changes to the silicon particle morphology and the concomitant surface area growth of the silicon particles approach a steady-state

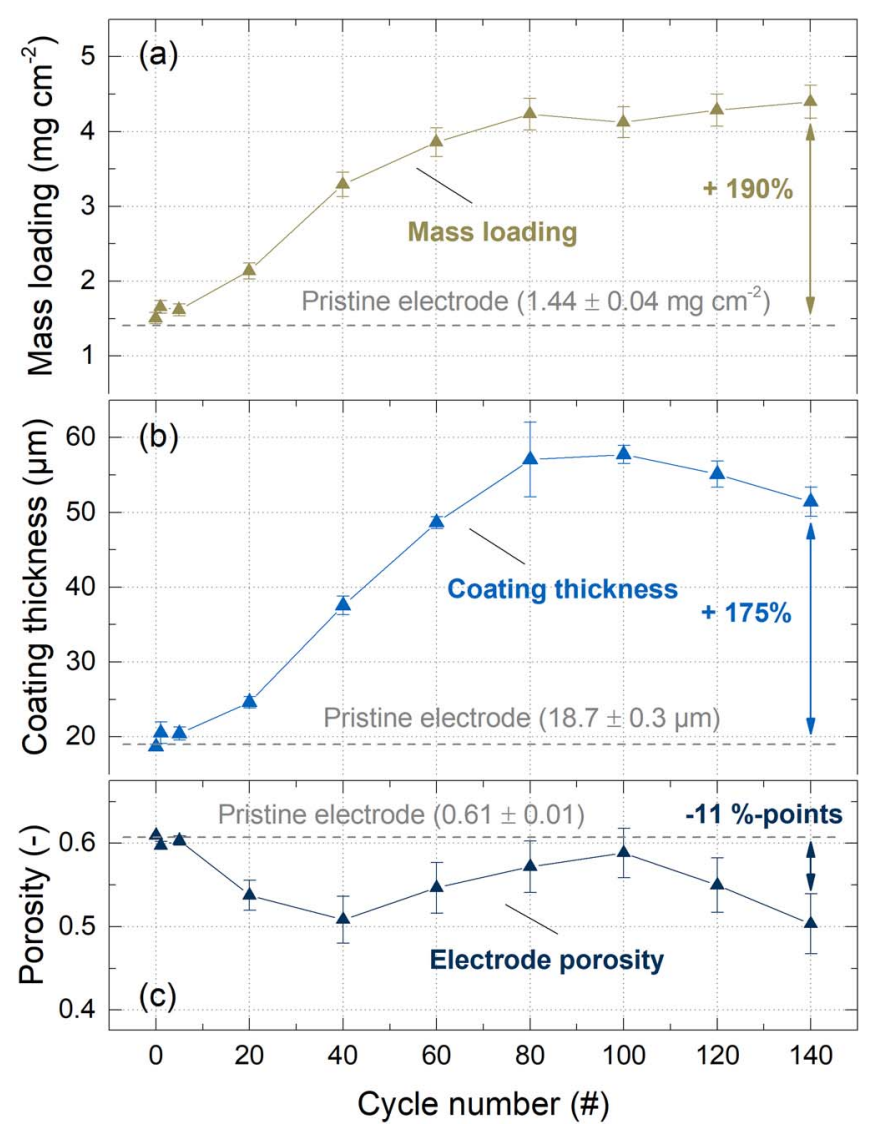

Figure 2. (a) Mass loading and (b) electrode thickness of the SiG electrodes measured post-mortem after different numbers of cycles, and (c) electrode porosity calculated from mass loading and electrode thickness. The error bars represent the following: (a) the standard error of $\pm 5 \%$ based on a larger number of electrodes from previous experiments, (b) the standard deviation of 15 repeat measurements along the cross-section of a single electrode, and (c) error propagation including the variance in the estimated density of the electrolyte decomposition products of $\pm 0.2 \mathrm{~g} \mathrm{~cm}^{-3}$.

condition, which is accompanied by a much reduced increase of the total irreversible capacity per cycle and by a consequent stabilization of the reversible capacity (see Figure 1a). Interestingly, Figure $2 \mathrm{c}$ indicates that the electrode porosity undergoes only a minor decrease from 0.61 to 0.5 over 140 cycles, which is comparatively small considering that the electrode mass loading almost triples during the cycling experiment. This is related to the fact that the electrode thickness also increased by a factor of $\sim 2.8$. In other words, the increased electrode volume resulting from the electrode swelling largely compensates the increased mass loading, leading to only minor changes in the electrode's porosity and thus the electrolyte volume fraction in the pores. As a corollary, any conclusions about the clogging of the pores in $\mathrm{SiG}$ electrodes should consider not only the SEI formation but also the swelling of the electrodes and, equally important, the distribution of the electrolyte decomposition products across the electrode thickness.

Neutron depth profiling of SiG electrodes.-FEC consumption measurements from a recent ${ }^{19} \mathrm{~F}-\mathrm{NMR}$ study demonstrated that the decomposition of electrolyte compounds at the silicon/electrolyte interface increases proportionally with the capacity exchanged by the silicon particles. ${ }^{7}$ The amount of these decomposition products can thus be used as a sensitive measure for the capacity utilization of the adjacent silicon active material. In other words, silicon particles that experience a larger change in their state-of-charge (SOC) during cycling, and thus also larger volumetric changes, consequently accumulate more electrolyte decomposition products. Since the SEI from the FEC-containing LP57 electrolyte consists mainly of 


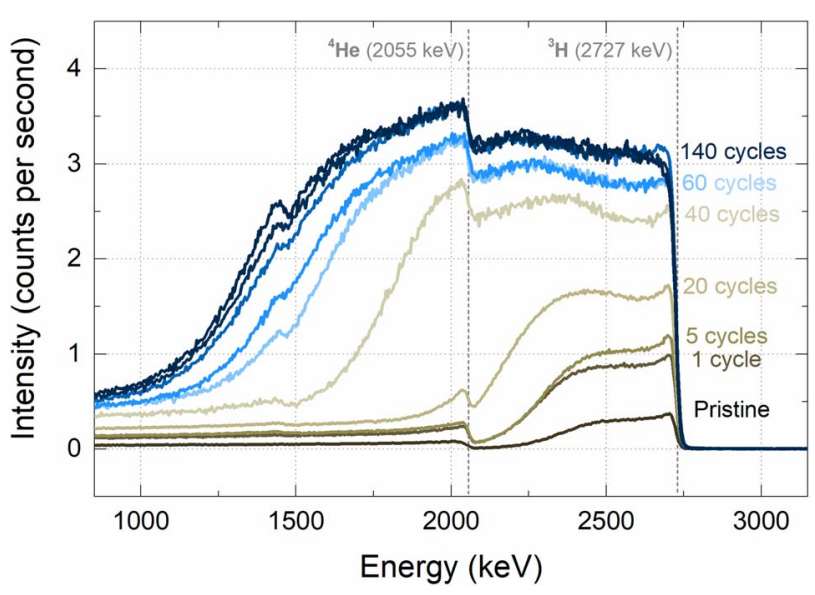

Figure 3. NDP energy spectra, showing the ${ }^{3} \mathrm{H}$ and ${ }^{4} \mathrm{He}$ intensity as a function of their energy for $\mathrm{SiG}$ electrodes measured ex-situ after different numbers of cycles (adapted from Trunk et al. ${ }^{33}$ ). The electrodes were aged according to the cycling protocol shown in Figure 1, whereby cycle number 1 represents the $\mathrm{SiG}$ electrode after the first formation cycle at a C-rate of $0.1 \mathrm{~h}^{-1}$. The vertical dashed lines show the formation energy of ${ }^{3} \mathrm{H}$ and ${ }^{4} \mathrm{He}$.

lithium-containing compounds from the reductive decomposition of FEC, e.g., $\mathrm{Li}_{2} \mathrm{CO}_{3}, \mathrm{LiF}$, and $\mathrm{Li}_{2} \mathrm{O},{ }^{17,31,32}$ a quantification of the lithium concentration profile across aged $\mathrm{SiG}$ electrodes thus allows to determine the evolution of the depth-resolved silicon capacity utilization upon cycling. For this reason, the lithium distribution across pristine and cycled $\mathrm{SiG}$ electrodes was determined by neutron depth profiling measurements. A thickness-independent lithium concentration would indicate a homogeneous formation of electrolyte decomposition products, which in turn would indicate a depth-independent capacity utilization of the active materials. In contrast, differences in the accessibility of the $\mathrm{SiG}$ anode upon aging would be indicated by a non-homogeneous lithium distribution. For example, a clogging of the electrolyte-filled pores by electrolyte decomposition products could lead to a lithium ion concentration gradient in the electrolyte phase during (de-)lithiation, which would favor the (de-)lithiation of silicon particles near the $\mathrm{SiG}$ anode/separator interface, as reported by Radvanyi et $\mathrm{al}^{20}$ and Michan et $\mathrm{al}^{21}$ for graphite-free silicon electrodes. On the other hand, an insufficient electrical conductivity across the electrode due to SEI build-up and electrode swelling would result in a higher active material utilization near the current collector/electrode interface, as shown by NDP for an electronically poorly conductive LFP electrode. ${ }^{30}$

Figure 3 shows the energy spectra obtained from NDP measurements of $\mathrm{SiG}$ electrodes which were aged for different numbers of cycles. In accordance with Equation 1, neutrons are absorbed by ${ }^{6} \mathrm{Li}$ to form an $\alpha\left({ }^{4} \mathrm{He}\right)$ and a triton $\left({ }^{3} \mathrm{H}\right)$ particle which are detected by a surface-barrier detector facing the free top-surface of the SiG electrode (opposite the $\mathrm{SiG}$ electrode/current collector interface) ${ }^{24}$ Due to the two-body kinematics, $\alpha$ and triton particles have well-defined energies at the moment of their formation and they are emitted backto-back. $^{23,24,37}$ The energy loss experienced by these particles while traveling through the electrode can therefore be used to measure the depth where the nuclear reaction has taken place. ${ }^{23,38}$ This energy loss can be described by the so-called stopping power, which is highly dependent on the nature of the charged particles, their energy, as well as on the properties of the material matrix through which they pass, namely its density and composition.

$$
{ }^{6} \mathrm{Li}+\mathrm{n} \rightarrow{ }^{4} \mathrm{He}(2055 \mathrm{keV})+{ }^{3} \mathrm{H}(2727 \mathrm{keV})
$$

Since the ${ }^{4} \mathrm{He}$ and ${ }^{3} \mathrm{H}$ particles are emitted isotropically, only one of them is detected at a time, but signals from both appear in the spectra. While the escape depth of ${ }^{4} \mathrm{He}$ particles through the porous $\mathrm{SiG}$ electrode is only $\sim 15 \mu \mathrm{m}$, that of the ${ }^{3} \mathrm{H}$ particles is much larger, ${ }^{39}$ having an escape depth of up to $\sim 50 \mu \mathrm{m}$ through the $\mathrm{SiG}$ electrode. ${ }^{33}$
In other words, the energy distribution profile obtained for the ${ }^{3} \mathrm{H}$ signal starts at $2727 \mathrm{keV}$ (corresponding to ${ }^{3} \mathrm{H}$ particles created at the top-surface of the $\mathrm{SiG}$ electrode) and continues to lower energy values for ${ }^{3} \mathrm{H}$ particles emanating from a greater depth in the $\mathrm{SiG}$ electrode; at an energy of $2055 \mathrm{keV}$, the ${ }^{3} \mathrm{H}$ signal will then overlap with the ${ }^{4} \mathrm{He}$ particle signal. A third signal was found to appear at $1472 \mathrm{keV}$ and determined to originate from boron impurities of the glass fiber separator, pieces of which were stuck on the top-surface of the harvested $\mathrm{SiG}$ electrodes. It was observed to increase with the cycle number, caused by the stronger adhesion of the fibers on the aged and roughened surface of the $\mathrm{SiG}$ electrodes. This was confirmed by the fact that no such signals were observed for pristine $\mathrm{SiG}$ electrodes as well as in reference measurements with boron-free poly(olefin)-based Celgard separators (data not shown).

In the pristine electrode (the lowest, dark brown line in Figure 3), in which the LiPAA binder is the only source of lithium, the ${ }^{4} \mathrm{He}$ and ${ }^{3} \mathrm{H}$ signals still occur at distinctly different energies and do not overlap. The high-energy onset for each signal represents particles emanating from the top-surface of the electrode, while signals at lower energies correspond to particles emanating from a greater depth. At $2727 \mathrm{keV}$, the ${ }^{3} \mathrm{H}$ signal jumps to $\sim 0.3 \mathrm{cps}$, followed by a slightly tilted plateau towards lower energies, which vanishes at $\sim 2100 \mathrm{keV}$; here, the location of the interface between the $\mathrm{Cu}$ current collector and the $\mathrm{SiG}$ electrode is marked on this energy scale by the inflection point of the decaying signal at around $2340 \mathrm{keV} .{ }^{33}$ The area below this signal can be ascribed to the total lithium content in the SiG electrode and the rather flat plateau of the ${ }^{3} \mathrm{H}$ signal vs. energy indicates a fairly uniform LiPAA distribution across the pristine electrode. At lower energies, the intensity jump at $2055 \mathrm{keV}$ shows the onset of the ${ }^{4} \mathrm{He}$ particle signal.

The curve just above the lowest in the same graph, labeled "1 cycle", shows the intensity vs. energy profile after the first charge/discharge cycle (delithiated to $2.0 \mathrm{~V}$ vs. $\mathrm{Li}^{+} / \mathrm{Li}$ at a very slow $\mathrm{C}$-rate of $0.02 \mathrm{~h}^{-1}$ ). The ${ }^{3} \mathrm{H}$ signal at $\sim 2727 \mathrm{keV}$ now increases from $\sim 0.3 \mathrm{cps}$ for the pristine electrode to $\sim 0.9 \mathrm{cps}$ at the plateau, indicating a considerable increase of the lithium content in the electrode. At the same time, however, the shape of the triton profile is still the same as in the pristine electrode, indicating that the distribution of the additional lithium containing species deposited in the SiG electrode is similarly uniform as that of the LiPAA binder. ${ }^{33}$ In fact, there are two possible causes for the additional amount of lithium in the SiG electrode, whereby both of them would result in an irreversible capacity loss: (i) lithium-containing electrolyte decomposition and SEI products formed at the electrode/electrolyte interface, and (ii) immobilized lithium remaining in the silicon active material due to kinetic overpotentials. ${ }^{40}$ As the $\mathrm{SiG}$ electrodes were measured in a fully discharged state after a very slow delithiation rate of $0.02 \mathrm{~h}^{-1}$ to a $\mathrm{SiG}$ electrode potential of $2.0 \mathrm{~V} \mathrm{vs}$. $\mathrm{Li}^{+} / \mathrm{Li}$, we conclude that the majority of the irreversible capacity loss must stem from the SEI rather than from immobilized lithium. This can be further supported by exemplarily considering the reversible capacity decay of the $\mathrm{SiG}$ electrode over 120 cycles (see Figure 1a). During the first cycle at $0.1 \mathrm{~h}^{-1}$, the electrode delivered a capacity of $1.66 \mathrm{mAh} \mathrm{cm}^{-2}$, whereas after 120 cycles the reversible capacity after a slow delithiation step to $2 \mathrm{~V}$ vs. $\mathrm{Li}^{+} / \mathrm{Li}$ at $0.02 \mathrm{~h}^{-1}$ amounted to $0.88 \mathrm{mAh} \mathrm{cm}^{-2}(\Delta=0.78 \mathrm{mAh}$ $\mathrm{cm}^{-2}$ ). Taking into account that the incomplete delithiation mainly affects silicon particles at low degrees of lithiation, i.e., below $\sim 25 \%$ state-of-charge, ${ }^{7}$ the estimated maximum contribution from immobilized lithium would be $\sim 0.20 \mathrm{mAh} \mathrm{cm}^{-2}$. This corresponds to just $\sim 9 \%$ of the total irreversible capacity of $2.13 \mathrm{mAh} \mathrm{cm}^{-2}$. Repeating this calculation for $\mathrm{SiG}$ electrodes after different number of cycles reveals the same fraction of $8-10 \%$, thus confirming our assumption.

After 5 cycles, the uniform lithium distribution across the SiG electrode remains, while the lithium content slightly increases which we assign to cracking and renewal of the passivating layer at the silicon/electrolyte interface caused by the volumetric changes of the silicon particles upon repeated (de-)lithiation. Towards 20 cycles, the lithium content further increases to $\sim 1.6 \mathrm{cps}$, while the shape of the signal remains essentially the same. In addition, the signal clearly 
broadens, shifting the inflection point of the ${ }^{3} \mathrm{H}$ signal towards lower energies, which indicates a further mass loading increase of the electrode; this also goes hand in hand with an increase in the lithium mass loading, as the total amount of lithium is proportional to the area under the curve in Figure 3. In agreement with the cycling data (see Figure 1a) and the electrode mass and thickness data (see Figure 2), the NDP spectra thus confirm that the largest changes in terms of the irreversible capacity loss as well as of the mass and thickness increase occur within the first 60 cycles.

Eventually, the ${ }^{3} \mathrm{H}$ signal overlaps with the onset of the ${ }^{4} \mathrm{He}$ signal, resulting in a shoulder at $2055 \mathrm{keV}$ as shown in Figure 3. Therefore, the depth profiles from the ${ }^{3} \mathrm{H}$ signal become hard to interpret beyond 60 cycles. For separation of the ${ }^{3} \mathrm{H}$ and ${ }^{4} \mathrm{He}$ signals, a thin Mylar or Kapton foil is commonly used which blocks the ${ }^{4} \mathrm{He}$ particles; however, at the same time it would also worsen the energy resolution of the ${ }^{3} \mathrm{H}$ signal. ${ }^{41}$ Instead, we performed a mathematical deconvolution of the ${ }^{3} \mathrm{H}$ and ${ }^{4} \mathrm{He}$ signal contribution to the recorded spectra: the two signals in Figure 3 were separated by describing the ${ }^{4} \mathrm{He}$ signal based on the distinct part of the triton signal above $2055 \mathrm{keV}$ which originates from the same depth information near the surface, as introduced by Trunk et al. ${ }^{33}$

As the intensity of the triton signal is strictly proportional to the number of ${ }^{6} \mathrm{Li}$ isotopes and therefore the number of lithium atoms in the $\mathrm{SiG}$ electrodes (calculated using the natural ${ }^{6} \mathrm{Li}$ abundance of $7.59 \%$ ), the latter was converted into an equivalent capacity (using 1 As of charge per mol of lithium). In the pristine electrode, the equivalent capacity of lithium in the LiPAA binder determined by the integrated lithium intensity from the NDP spectrum was found to be $0.058 \pm 0.002 \mathrm{mAh} \mathrm{cm}^{-2}$. Since the observed energy loss in combination with the Stopping Range in Matter (SRIM) approach ${ }^{33,37}$ also allows to calculate an equivalent mass loading of the pristine $\mathrm{SiG}$ electrode of $1.65 \pm 0.34 \mathrm{mg} \mathrm{cm}^{-2}$, the equivalent capacity of lithium in the LiPAA binder can also be determined by multiplying the thus found mass loading with the LiPAA content of $10 \mathrm{wt} \%$ and dividing it by its molecular weight $\left(M_{W}=77.9 \mathrm{~g} \mathrm{~mol}^{-1}\right)$. This yields an equivalent capacity of $\sim 0.057 \mathrm{mAh} \mathrm{cm}{ }^{-2}$, which is in excellent agreement with the above value from the integrated lithium signal intensity. Furthermore, while the NDP-derived mass loading of $1.65 \pm 0.34 \mathrm{mg} \mathrm{cm}^{-2}$ for the pristine $\mathrm{SiG}$ electrode is $\sim 15 \%$ larger than the value obtained by weighing of the pristine $\mathrm{SiG}$ electrode $\left(1.44 \pm 0.04 \mathrm{mg} \mathrm{cm}^{-2}\right.$, see Figure $2 \mathrm{a}$ ), this agreement is reasonably good considering the overall rather low lithium mass loading $\left(\sim 10 \mu \mathrm{g} / \mathrm{cm}^{2}\right)$ in the pristine $\mathrm{SiG}$ electrode. From here on forward, the total irreversible capacity of the cycled electrodes was calculated from the NDP signal intensities by subtracting the initial lithium content from the LiPAA binder (i.e., $0.058 \mathrm{mAh} \mathrm{cm}^{-2}$ ).

Figure 4a summarizes the total irreversible capacity obtained by the above outlined NDP analysis (marine symbols; assuming 1 As of total irreversible capacity per mol of lithium after subtraction of the LiPAA binder contribution) and the total irreversible capacity obtained from the electrochemical measurements of the respective electrodes (blue symbols; note the excellent agreement with the irreversible capacity vs. cycle number shown for one of the electrodes in Figure 1a). A rapid increase of the irreversible capacity is observed in the first 60 cycles, as was already seen in Figure 1a. Further cycling results in decreasing irreversible capacity gain per cycle (i.e., a "flattening" of the curve), indicating a decrease of the extent of side reactions at the silicon/electrolyte interface. ${ }^{10}$ In general, the irreversible capacity values monitored by the two methods agree fairly. The $\sim 20 \%$ lower total irreversible capacity values obtained by NDP may have two possible reasons: (i) The NDP signals derive only from the center of the electrode $\left(\sim 0.18 \mathrm{~cm}^{2}\right.$ of $\left.1.54 \mathrm{~cm}^{2}\right),{ }^{33}$ whereas the electrochemical method averages over the entire electrode surface, thus any inhomogeneities at the electrode edges are not considered by NDP. (ii) A partial mechanical removal of the coating and electrolyte decomposition products either by washing after disassembly or during the transport from the glovebox to the NDP experiment.

To determine the distribution of the lithium-containing electrolyte decomposition products across the thickness of the SiG electrodes,

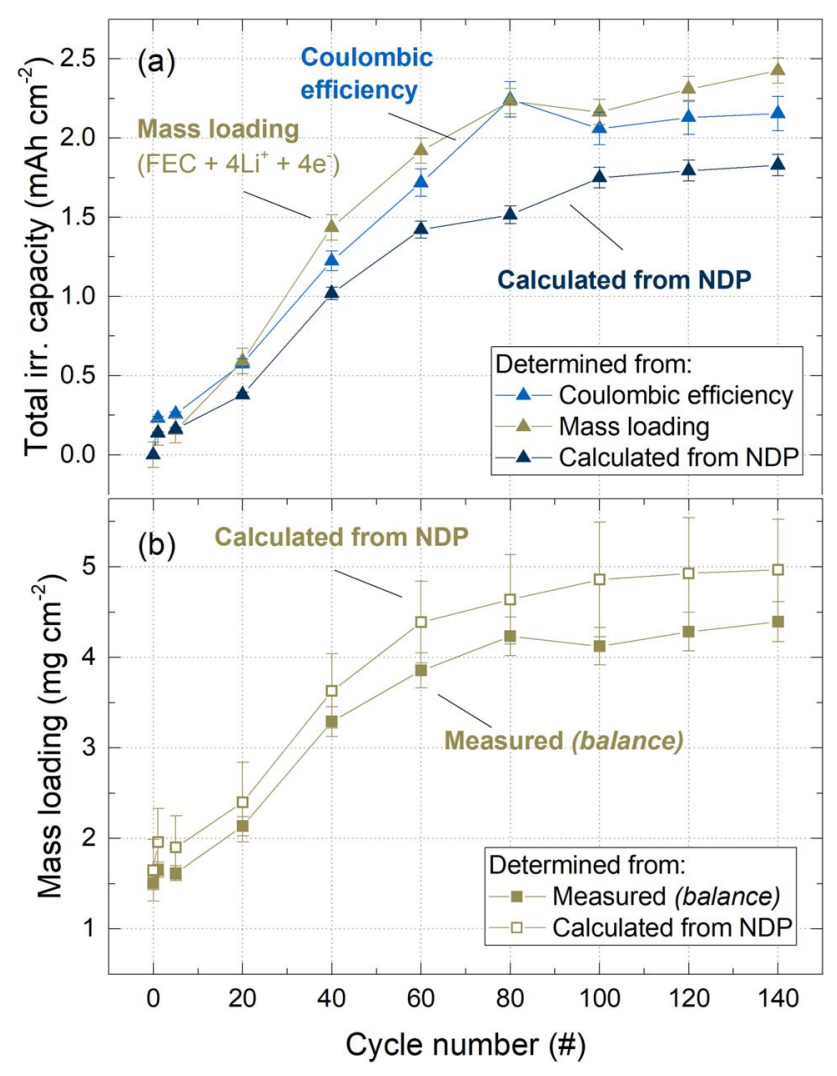

Figure 4. (a) Total irreversible capacity of the $\mathrm{SiG}$ electrode as a function of the cycle number determined from: (i) the integration of the coulombic efficiency over cycle number during galvanostatic cycling (blue symbols); (ii) the post-mortem electrode mass loading measurements and assuming a four-electron reduction mechanism of FEC described by Equation 2 (brown symbols); and, (iii) the lithium intensity measured by ex-situ NDP after correction for the lithium intensity originating from the LiPAA binder of $0.058 \mathrm{mAh} \mathrm{cm}^{-2}$ (marine symbols). (b) Mass loading of the $\mathrm{SiG}$ electrodes as a function of the cycle number measured with a balance (solid symbols, taken from Figure $2 \mathrm{a}$ ) or computed from the NDP spectra (hollow symbols). For the mass loading and the coulombic efficiency, a standard error of $\pm 5 \%$ was used based on a larger number of electrodes and measurements in a previous study. For the NDP measurements, an error propagation was calculated considering the signal processing and the definition of the inflection points.

the mathematically separated ${ }^{3} \mathrm{H}$ spectra (removing the ${ }^{4} \mathrm{He}$ and ${ }^{10} \mathrm{~B}$ contributions) were converted into a lithium density (in units of $\mathrm{Li}$ atoms $\mathrm{cm}^{-3}$ ), ${ }^{33}$ assuming natural ${ }^{6} \mathrm{Li}$ abundance and uniform electrode porosity, and plotted against the electrode mass loading (in $\mathrm{m} \mathrm{cm}^{-2}$ ), which is shown in Figure 5a. The energy-loss model is based on the SRIM calculation and described elsewhere. ${ }^{33,37}$ By this approach, the full depth evolution even for cycles where the signals were previously superimposed can now be studied. In accordance with the increasing fraction of electrolyte decomposition products which accumulate in the porous electrode upon cycling, the changing composition of the SiG electrode has to be taken into account for the SRIM calculation of each cycle. For that purpose, a recent publication by Petibon et al. ${ }^{6}$ was considered, who, based on gas chromatography (GC) measurements, reported that FEC is the major electrolyte compound which gets reduced on silicon at potentials below $1.0 \mathrm{~V}$ vs. $\mathrm{Li}^{+} / \mathrm{Li}$, yielding electrolyte decomposition products with an overall stoichiometry of $\mathrm{C}_{3} \mathrm{H}_{3} \mathrm{O}_{3} \mathrm{~F}$. Although initially gaseous carbon dioxide $\left(\mathrm{CO}_{2}\right)$ is evolved during FEC reduction, ${ }^{6,8}$ Krause et al. ${ }^{42}$ reported that $\mathrm{CO}_{2}$ gets reduced at the silicon surface and thus also becomes part of the SEI. Because the overall FEC reduction was shown by Jung et al. ${ }^{8}$ to consume a total of four electrons per FEC molecule, the stoichiometry of the final reduction products was complemented by four additional lithium ions to restore charge neutrality, 

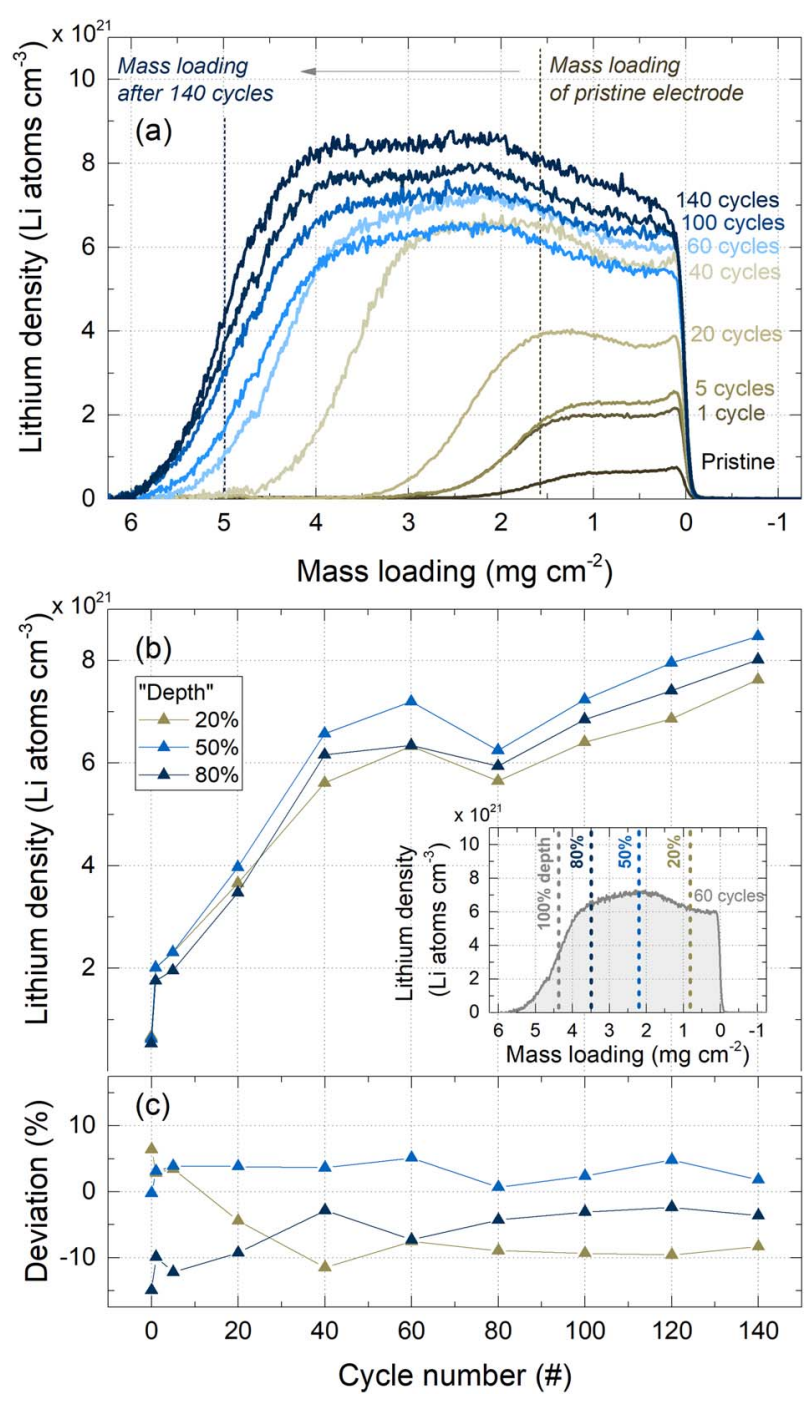

Figure 5. (a) Lithium density distribution as a function of the electrode mass loading (in $\mathrm{m} \mathrm{cm}^{-2}$ ) of SiG electrodes measured ex-situ by NDP after different numbers of cycles. (b) Lithium density at 20,50 , and $80 \%$ of the electrode mass loading ("depth") referenced to the electrode top-surface as a function of the cycle number, obtained from the lithium density distribution shown in (a), which is illustrated in the inset in (b). (c) Deviation of the lithium density at 20,50 , and $80 \%$ from the mean lithium density.

yielding an overall stoichiometry of $\mathrm{C}_{3} \mathrm{H}_{3} \mathrm{O}_{3} \mathrm{FLi}_{4}$. To verify that this four-electron reduction mechanism can also be applied in the present work, Equation 2 was used to calculate the capacity $Q_{S E I}$ which would correspond to the increase in electrode mass loading $L_{S E I}$ shown in Figure $2 \mathrm{a}$ (determined by post-mortem weight measurements):

$$
\mathrm{Q}_{\mathrm{SEI}}=\frac{\mathrm{L}_{\mathrm{SEI}}}{\mathrm{M}_{\mathrm{SEI}}} \times \mathrm{z} \times \mathrm{F}
$$

where $M_{S E I}$ the molecular weight of the electrolyte decomposition products with the overall stoichiometry of $\mathrm{C}_{3} \mathrm{H}_{3} \mathrm{O}_{3} \mathrm{FLi}_{4}\left(M_{W}\right.$ $\left.=133.81 \mathrm{~g} \mathrm{~mol}^{-1}\right){ }^{7} z$ the number of electrons (here: 4 ), and $F$ is the Faradaic constant. Figure 4a shows the resulting total irreversible capacity $Q_{S E I}$ (brown symbols), which is in good agreement with the values obtained by integrating the measured coulombic efficiency (blue symbols) and thus supports the above made assumptions on the overall SEI stoichiometry.

The electrode mass loadings shown in Figure 5a, as calculated from the NDP energy spectra, were also compared to the mass loadings which were measured by weighing of harvested $\mathrm{SiG}$ electrodes (compare Figure 2a). This is exemplarily shown by the vertical dashed lines, marking the NDP spectra inflection points for the pristine $\mathrm{SiG}$ electrode and the electrode after 140 cycles, respectively. Figure $4 \mathrm{~b}$ summarizes the corresponding inflection points for all electrode mass loadings (hollow symbols) determined by NDP and the mass loadings obtained by weighing harvested electrodes (solid symbols) as a function of the cycle number, showing excellent agreement between the NDP-based and the weight measurement-based values.

The lithium density profiles shown in Figure 5a indicate the same two major trends that were previously discussed for the NDP energy spectra, namely (i) an increase in the local lithium density at any given electrode depth due to the accumulation of electrolyte decomposition products, and (ii) a concomitant mass loading increase of the entire electrode upon cycling. In addition, the lithium density profiles of the first 20 cycles indicate an almost uniform lithium distribution across the thickness of the $\mathrm{SiG}$ electrodes, while after more cycles a $\sim 15 \%$ lower lithium density can be observed at the top-surface of the $\mathrm{SiG}$ electrodes. This phenomenon likely originates from the rapid swelling of the electrodes particularly after 20 cycles (see Figure $2 \mathrm{a}$ and Figure 6) which may cause that some of the already detached particles or electrolyte decomposition products remain in the inner layers of the electrodes. Overall, however, the lithium concentration across the cycled $\mathrm{SiG}$ electrodes, as revealed by Figure 5a is surprisingly homogeneous. This can be seen more clearly in Figure 5b, which summarizes the lithium density evolution over cycling at different electrode depths of 20,50, and $80 \%$ referenced to the top-surface of the $\mathrm{SiG}$ electrode (100\% equals the mass loading calculated from NDP which is shown in Figure 4b). In agreement with the capacity fading rates and the total irreversible capacity growth rates shown in Figure 1a, the largest increase in the lithium density from $\sim 0.7$ to $\sim 6.0 \times 10^{21}$ $\mathrm{Li}$ atoms $\mathrm{cm}^{-3}$ occurs within the first 60 cycles. However, continued cycling reveals a much smaller increase to $\sim 8.0 \times 10^{21} \mathrm{Li}$ atoms $\mathrm{cm}^{-3}$ after 140 cycles. Remarkably, despite the slightly lower lithium density towards the surface of the electrode (i.e., at $20 \%$ electrode depth), the distribution of the lithium atoms remains widely constant across the electrode even upon extended cycling. This is illustrated more clearly by Figure 5c showing only small deviations of less than $15 \%$ from the mean lithium density across the electrode coatings.

From this it can be concluded that apart from the small deviation at the electrode top-surface, the lithium containing electrolyte decomposition products are almost uniformly distributed across the $\mathrm{SiG}$ electrode coatings even upon extended cycling. Since the amount of electrolyte decomposition products is proportional to the capacity exchanged by the silicon particles, ${ }^{7}$ one can conclude that the silicon active material utilization over the 140 cycles must also be homogeneous across the $\mathrm{SiG}$ electrode thickness, so that the occurrence of significant transport-limitations which would lead to an inhomogeneous silicon utilization can be excluded for the here investigated aged SiG electrodes. This supports a previous work from our group, ${ }^{7}$ according to which the incomplete delithiation from electronically poorly connected silicon particles in $\mathrm{SiG}$ electrodes is the main cause for the capacity decay within the first 60 cycles, presuming an excess of active lithium from the positive electrode. Because the network of graphite particles provides a reasonable electrode porosity and electrical conductivity even across substantially swollen $\mathrm{SiG}$ electrodes, the major capacity fading mechanism for these $\mathrm{SiG}$ electrodes are electronic contact resistances occurring between the silicon particles due to insufficient interparticle contact pressure at low degrees of lithiation. These contact resistances are expected to grow with cycling due to SEI build-up, and since this phenomenon is independent of the location of the silicon particles, this aging mechanism does predict the here observed homogeneous silicon utilization across the thickness of the electrode.

It must be noted, however, that this finding seems to contradict some results in the literature where clogging of electrode pores by SEI products was stated to lead to an inhomogeneous silicon utilization across the electrode. ${ }^{15,20,21}$ However, the discrepancy to these studies from Oumellal et al., ${ }^{15}$ Radvanyi et al., ${ }^{20}$ and Michan et al. ${ }^{21}$ likely originates from the absence of large graphite particles in the respective silicon-based electrodes (using either only carbon black 


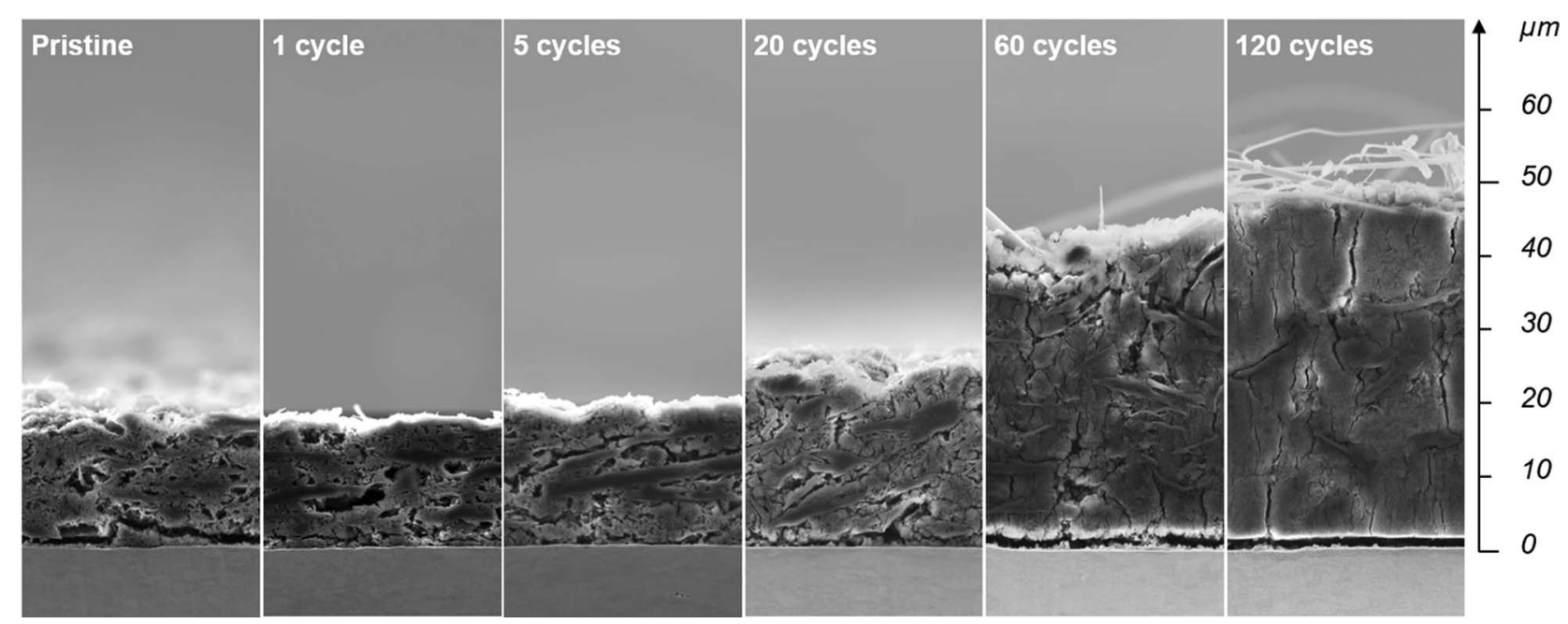

Figure 6. Cross-sectional SEM images of SiG electrodes in the pristine state and after different numbers of cycles at a magnification of 1000x. Recorded with a secondary electron detector and an acceleration voltage of $10 \mathrm{kV}$.

or carbon fibers), which increases the risk of a deterioration of the electronic conductivity across the thickness of the electrode upon extensive SEI formation as well as a loss of void volume in the vicinity of the sterically demanding graphite particles. In addition, Oumellal and Radvanyi also used capacity-limited cycling procedures which bear the risk of an inhomogeneous (de-)lithiation of silicon particles, because only a fraction of the available capacity is utilized during each cycle, likely resulting in more charge/discharge of well-connected particles compared to others.

Morphological changes of SiG electrodes upon cycling.-To support our above interpretation of the electrode property changes (see Figure 2) and the lithium density profiles across the electrode (see Figure 5) upon extended cycling, cross-sections of the $\mathrm{SiG}$ electrodes were investigated by means of scanning electron microscopy (SEM). Figure 6 shows representative sections of the SEM images (1000x magnification) of electrodes before and after a different number of charge/discharge cycles. The SEM cross-sections (Figure 6) show that the major increase in the thickness of the $\mathrm{SiG}$ electrode occurs between 20 and 60 cycles, analogous to what was shown in Figure $2 b$. It is to note that the values shown in Figure $2 b$ represent the average of the entire cross-section of the resign-embedded halved pieces of the electrodes, whereas the argon ion beam polished images shown in Figure 6 only refer to a section of $\sim 500 \mu \mathrm{m}$ length from the center of the other piece of the electrode, from which only $\sim 30 \mu \mathrm{m}$ are shown in the images. The SEM cross-sections indicate that the SiG electrodes accumulate a large amount of electrolyte decomposition products upon cycling. As expected from the volumetric changes upon repeated (de-)lithiation, the silicon nanoparticles are increasingly covered by SEI products and thus not any more visible as single entities, whereas most of the large graphite particles can still be distinguished well. In accordance with the lithium depth profiles, the SEM cross-sections reveal a rather uniform distribution of the electrolyte decomposition products across the thickness of the $\mathrm{SiG}$ electrodes up to the shown 120 cycles.

Another striking observation from these images is that with an increasing cycle number the graphite particles are no longer horizontally aligned, but instead are partially displaced and become randomly oriented as the swelling of the SiG electrodes proceeds. This, we believe, is a consequence of the homogeneous growth of the SEI across the thickness of the SiG electrode: as each graphite particle faces the same forces which depend only on the statistical distribution of the silicon particles, a random orientation of the graphite particles results as the electrode thickness is increasing due to the irreversible expansion of the silicon particles over the first $\sim 60$ cycles and the accumulation of electrolyte degradation products. ${ }^{10}$
In summary, these cross-sectional SEM images further support our interpretation of the NDP spectra, according to which the silicon active material is utilized homogeneously across the entire SiG electrode, without any indication of a reduced silicon accessibility either near the current collector (driven by insufficient through-plane conductivity $)^{30}$ or near the electrode top-surface adjacent to the separator (driven by pore clogging). ${ }^{15}$ Nonetheless, the similar utilization of the silicon particles is likely only sustained by the network of large graphite particles that maintains a sufficient porosity and electrical conductivity across the thickness of the electrode. As a corollary, further optimization of silicon-based electrodes in terms of the electrical conductivity requires not only a sufficient electrical connection of the individual silicon particles to overcome interparticle contact resistances, but also to ensure a contiguous network of well-conducting graphite particles to minimize the mean path length that electrons need to travel between the individual silicon particles and graphite. This finding is in good agreement with our previous publication ${ }^{7}$ where we showed that a lower silicon/graphite ratio significantly improves the cycling stability of these electrodes.

Figure 7 shows cross-sectional images of the same SiG electrodes at a higher magnification of 5000x. By comparing the electrodes in the pristine state and after 5 cycles, it can be clearly seen that the SEI preferably accumulates near the silicon particles, which has also been reported by Michan et al. ${ }^{21}$ In contrast, no SEI accumulation can be observed at the edges of the graphite particles, thus preserving some void space in the coating. Further, the precipitation of electrolyte decomposition products around the silicon particles seems to occur evenly across the thickness of the electrode, consistent with the NDP analysis. While initially individual silicon particles can still be discerned, this becomes increasingly difficult after 20 cycles, which in part is due to the fact that the silicon particles expand irreversibly into a network of nanometer-sized silicon branches interpenetrated by electrolyte decomposition products, as was shown in a previous TEM study. ${ }^{10}$ After 60 and even more so after 120 cycles, the electrolyte decomposition products and silicon particles merge into apparently dense agglomerates that have also been observed by Radvanyi et al. ${ }^{20}$ As a matter of fact, however, SEM images of the electrode after 120 cycles at higher magnification of 15'000x and 50'000x (see Figure 8), reveal that these agglomerates are not dense, but instead are porous, foam-like structures consisting of silicon covered by electrolyte decomposition products (more clearly visible in our previous TEM analysis). ${ }^{10}$

Because the remaining pores are still on the order of $10^{1}-10^{2}$ nanometers, they can be easily penetrated by electrolyte; their presence also explains that the porosity of the electrodes even after 140 cycles remains as high as $\sim 50 \%$ (see Figure $2 \mathrm{c}$ ). An unexpected con- 

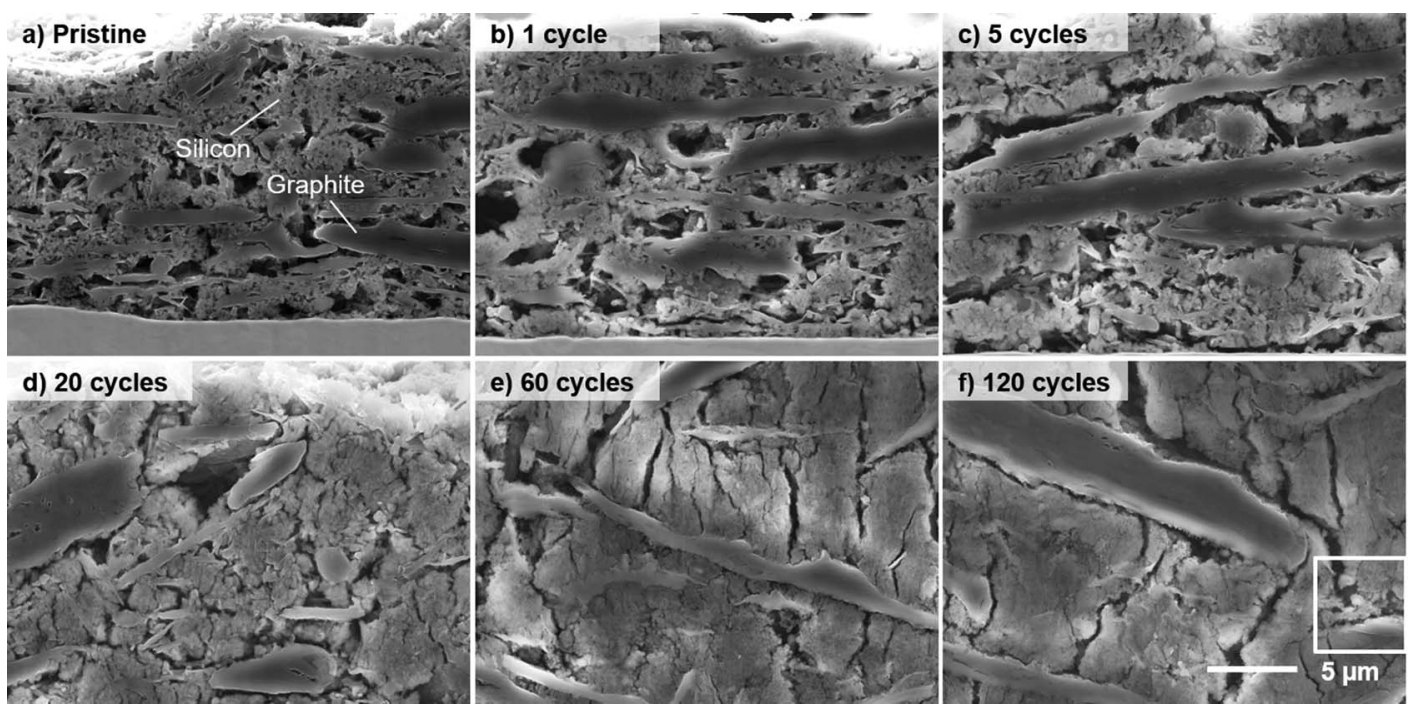

Figure 7. Cross-sectional SEM images of SiG electrodes in the pristine state and after different numbers of cycles at a magnification of 5000x. The white frame in (f) indicates the location of measurements taken with a higher magnification and shown in Figure 8. Recorded with a secondary electron detector and an acceleration voltage of $10 \mathrm{kV}$.

sequence of the high remaining porosity in combination with the substantial electrode swelling is that the total pore volume contained in the cycled $\mathrm{SiG}$ electrodes is increasing upon repeated charge/discharge cycling rather than decreasing. Considering a pristine SiG electrode with a coating thickness of $\sim 19 \mu \mathrm{m}$ and a porosity of $\sim 60 \%$ (see Figure 2), the initial pore volume of the electrode equates to $\sim 1.1 \mu \mathrm{L} \mathrm{cm} \mathrm{cm}^{-2}$, while it increases to $\sim 2.6 \mu \mathrm{L} \mathrm{cm}{ }^{-2}$ after 140 cy-
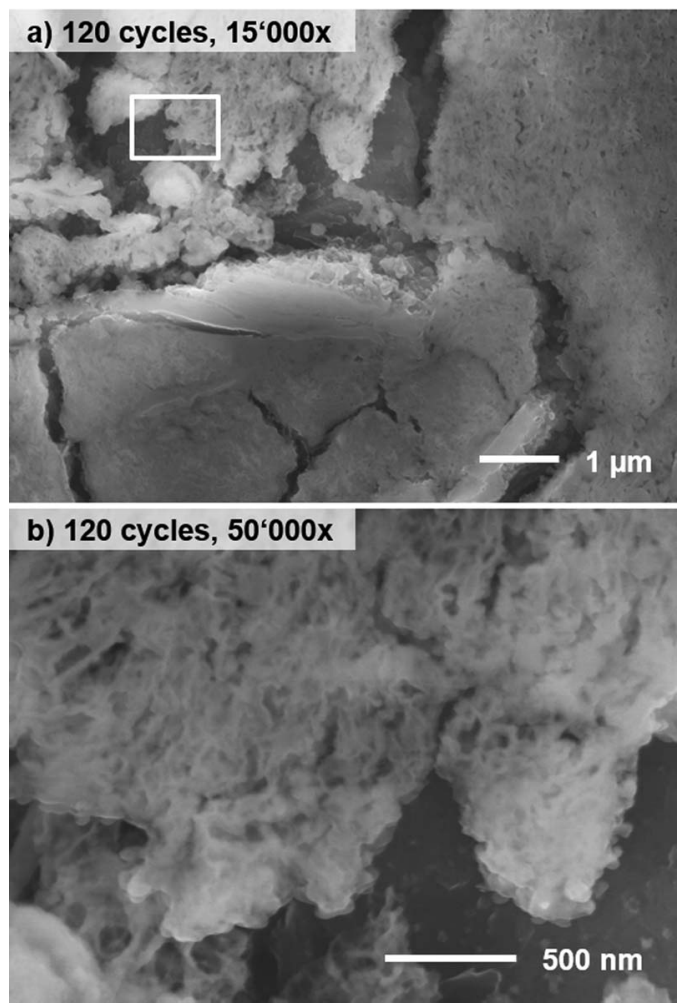

Figure 8. Cross-sectional SEM images of SiG electrodes after 120 cycles with a magnification of (a) $15^{\prime} 000 x$ and (b) 50'000x. The white frame in (a) indicates the location of measurement taken with the higher magnification, which is shown in (b). Recorded with a secondary electron detector and an acceleration voltage of $10 \mathrm{kV}$. cles (based on a thickness of $\sim 51 \mu \mathrm{m}$ and a porosity of $\sim 50 \%$; see Figure 2). While the higher pore volume in principle should allow for facile lithium ion transport across the electrode thickness in the electrolyte phase, it has a rather noteworthy corollary when comparing the capacity fading of battery cells with silicon-based anodes measured in coin-cells (or other lab-scale cell hardware) and large-scale cells. In coin-cells, the added amount of electrolyte typically exceeds the void volume provided by the electrodes and the separator(s) by $\sim 10$-fold, so that the increasing electrode void volume upon cycling can easily be replenished by the excess electrolyte. On the other hand, in large-scale cells, the electrolyte volume typically exceeds the total void volume of electrodes and separator by only $\sim 20 \%$, so that the here observed $\sim 2.5$-fold increase in anode void volume would lead to a partial dry-out of the electrodes, which in turn should result in a more accelerated capacity fading. Thus, one would expect that the typically much shorter cycle life of large-scale vs. lab-scale cells with silicon anodes is not only due to the more rapid consumption of stabilizing additives like FEC, ${ }^{6,8}$ but also due to the electrode swelling induced dry-out of the electrodes.

In summary, the above discussed phenomena underline the need for an integral design of silicon-based electrodes, considering both (i) a suppression of the degradation of the silicon particles and subsequent side reactions at the silicon/electrolyte interface, and (ii) a hierarchical electrode structure that maintains sufficiently low electron and lithium-ion transport resistances not only across the thickness of the electrode but also between the individual silicon particles. While the NDP analysis indicates that the performance of the here investigated $\mathrm{SiG}$ electrodes is not significantly compromised by transport resistances across the thickness of the electrode even at a relatively high C-rate of $0.5 \mathrm{~h}^{-1}$, the ongoing electrolyte decomposition at the silicon/electrolyte interface and the loss of interparticle contact pressure remain the major challenges for silicon-based electrodes.

\section{Conclusions}

In the present study, silicon-graphite ( $\mathrm{SiG})$ electrodes with an areal delithiation capacity of $\sim 1.7 \mathrm{mAh} \mathrm{cm}^{-2}$ were investigated in terms of their morphological changes and the distribution of lithiumcontaining electrolyte decomposition products as a function of the cycle number. Using ex-situ neutron depth profiling (NDP) on pristine and cycled electrodes in the discharged state, it was demonstrated that the aging of the $\mathrm{SiG}$ electrodes is most pronounced within the first 60 cycles. During this period, the silicon nanoparticles undergo se- 


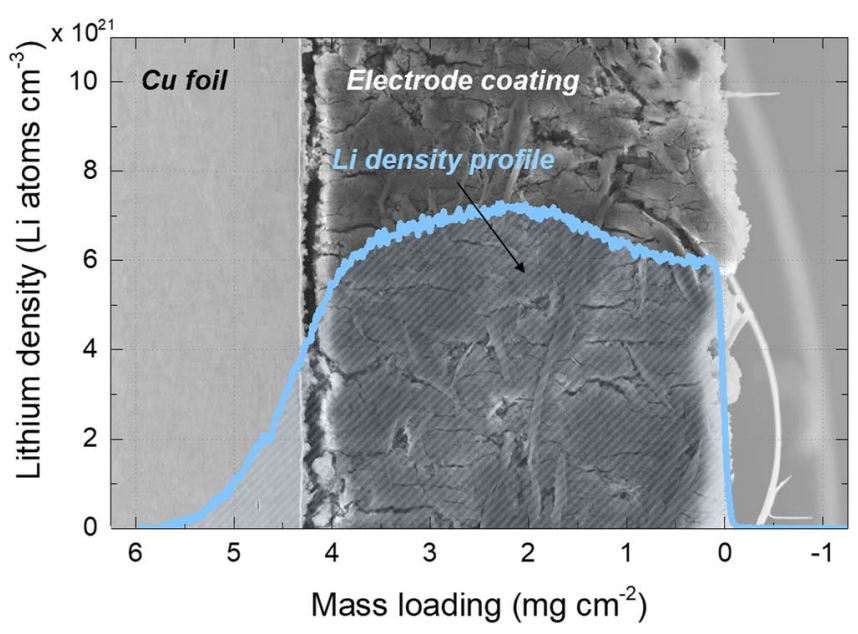

Figure 9. Lithium density profile of a SiG electrode after 60 charge/discharge cycles as a function of the electrode mass loading (blue line), exemplarily shown superimposed onto the corresponding cross-sectional SEM image. The profile is a convolution of the density with the material-dependent resolution, which includes an energy spread due to the statistical process of the energy loss and possibly also because of a slight variation in the local mass loading of the electrode. Thus, there is no lithium in the $\mathrm{Cu}$ current collector.

vere morphological changes which fuel side-reactions occurring at the silicon/electrolyte interface interface. The subsequent accumulation of large amounts of electrolyte decomposition products in the $\mathrm{SiG}$ electrodes could be followed quantitatively by NDP, which is exemplarily shown in Figure 9.

The depth-resolved lithium density profiles obtained in this way revealed a uniform distribution of the lithium-containing electrolyte decomposition products across the thickness of the $\mathrm{SiG}$ electrodes up to 140 charge/discharge cycles. As a corollary, the silicon active material was uniformly utilized across the SiG electrode thickness, demonstrating the absence of significant transport resistances (electronic or ionic) across the thickness of the investigated $\mathrm{SiG}$ electrodes even upon extended cycling. Instead, these findings suggest that the capacity decay of the $\mathrm{SiG}$ electrodes stems from the loss of interparticle contact pressure and increases with an increasing mean path length between individual silicon particles and adjacent electrically well-conducting graphite particles, which occurs statistically in a homogeneous electrode coating. High-resolution cross-sectional SEM images at different magnifications supported the interpretation of the uniform $\mathrm{SiG}$ electrode aging.

Finally, post-mortem weight, thickness and SEM cross-sectional studies of cycled SiG electrodes revealed that the electrode porosity remained almost unchanged over extended charge/discharge cycling. Owing to the significant swelling of the electrodes, the void volume of the pores even increased, which has important implications for the electrolyte amount in large-scale cells with $\mathrm{SiG}$ electrodes.

\section{Acknowledgments}

The authors kindly acknowledge Dr. Tristan Harzer and Dr. Susanne Cornfine (both JEOL Germany $\mathrm{GmbH}$ ) for the preparation and measurement of the cross-sectional SEM images. Wacker Chemie AG is kindly acknowledged for providing the silicon nanoparticles. The Heinz Maier-Leibnitz Zentrum (MLZ) is kindly acknowledged for the possibility to use the high-quality neutron beam at the PGAA facility. The authors acknowledge the financial support by the Federal Ministry of Education and Research (project numbers 05K16WO1 "N4DP" and 03XP0081 "ExZellTUM II") as well as by the Federal Ministry for Economic Affairs and Energy (project number 03ET6045D “LiMo").

\section{ORCID}

Morten Wetjen (D) https://orcid.org/0000-0002-2357-1151

\section{References}

1. O. Gröger, H. A. Gasteiger, and J.-P. Suchsland, J. Electrochem. Soc., 162(14), A2605 (2015).

2. K. G. Gallagher, S. Goebel, T. Greszler, M. Mathias, W. Oelerich, D. Eroglu, and V. Srinivasan, Energy Environ. Sci., 7, 1555 (2014).

3. D. Andre, S.-J. Kim, P. Lamp, S. F. Lux, F. Maglia, O. Paschos, and B. Stiaszny, J. Mater. Chem. A, 3, 6709 (2015).

4. M. N. Obrovac and V. L. Chevrier, Chem. Rev., 114, 11444 (2014)

5. F. Luo, B. Liu, J. Zheng, G. Chu, K. Zhong, H. Li, X. Huang, and L. Chen, J. Electrochem. Soc., 162(14), A2509 (2015).

6. R. Petibon, V. Chevrier, C. P. Aiken, D. S. Hall, S. Hyatt, R. Shunmugasundaram, and J. R. Dahn, J. Electrochem. Soc., 163(7), A1146 (2016).

7. M. Wetjen, D. Pritzl, R. Jung, S. Solchenbach, R. Ghadimi, and H. A. Gasteiger, J. Electrochem. Soc., 164(12), A2840 (2017).

8. R. Jung, M. Metzger, D. Haering, S. Solchenbach, C. Marino, N. Tsiouvaras, C. Stinner, and H. A. Gasteiger, J. Electrochem. Soc., 163(8), A1705 (2016).

9. Z. Du, R. A. Dunlap, and M. N. Obrovac, J. Electrochem. Soc., 161(10), A1698 (2014).

10. M. Wetjen, S. Solchenbach, D. Pritzl, J. Hou, V. Tileli, and H. A. Gasteiger, J. Electrochem. Soc., 165(7), A1503 (2018).

11. T. D. Hatchard and J. R. Dahn, J. Electrochem. Soc., 151(6), A838 (2004).

12. M. N. Obrovac and L. Christensen, Electrochem. Solid-State Lett., 7(5), A93 (2004).

13. B. Key, R. Bhattacharyya, M. Morcrette, V. Sezne, J. Tarascon, and C. P. Grey, J. Am. Chem. Soc., 131, 9239 (2009).

14. B. Key, M. Morcrette, J.-M. Tarascon, and C. P. Grey, J. Am. Chem. Soc., 133, 503 (2011).

15. Y. Oumellal, N. Delpuech, D. Mazouzi, N. Dupré, J. Gaubicher, P. Moreau, P. Soudan, B. Lestriez, and D. Guyomard, J. Mater. Chem., 21, 6201 (2011).

16. N. Delpuech, D. Mazouzi, N. Dupre, P. Moreau, M. Cerbelaud, J. S. Bridel, E. De Vito, D. Guyomard, B. Lestriez, and B. Humbert, J. Phys. Chem. C, 118, 17318 (2014).

17. K. W. Schroder, H. Celio, L. J. Webb, and K. J. Stevenson, J. Phys. Chem. C, 116, 19737 (2012).

18. M. Nie, D. P. Abraham, Y. Chen, A. Bose, and B. L. Lucht, J. Phys. Chem. C, 117, 13403 (2013).

19. S. Komaba, N. Yabuuchi, T. Ozeki, Z. J. Han, K. Shimomura, H. Yui, Y. Katayama, and T. Miura, J. Phys. Chem. C, 116, 1380 (2012).

20. E. Radvanyi, W. Porcher, E. De Vito, A. Montani, S. Franger, and S. Jouanneau Si Larbi, Phys. Chem. Chem. Phys., 16, 17142 (2014).

21. A. L. Michan, G. Divitini, A. J. Pell, M. Leskes, C. Ducati, and C. P. Grey, J. Am. Chem. Soc., 138, 7918 (2016).

22. E. Peled and S. Menkin, J. Electrochem. Soc., 164(7), A1703 (2017).

23. J. P. Biersack, D. Fink, R. Henkelmann, and K. Müller, Nucl. Instruments Methods, 149, 93 (1978).

24. R. G. Downing, G. P. Lamaze, J. K. Langland, and S. T. Hwang, J. Res. Natl. Inst. Stand. Technol., 98(1), 109 (1993).

25. J. F. M. Oudenhoven, F. Labohm, M. Mulder, R. A. H. Niessen, F. M. Mulder, and P. H. L. Notten, Adv. Mater, 23(35), 4103 (2011).

26. S. Whitney, S. R. Biegalski, Y. H. Huang, and J. B. Goodenough, J. Electrochem. Soc., 156(11), A886 (2009).

27. S. M. Whitney, S. R. F. Biegalski, and G. Downing, J. Radioanal. Nucl. Chem., 282, 173 (2009).

28. J. Wang, D. X. Liu, M. Canova, R. G. Downing, L. R. Cao, and A. C. Co, J.Radioanal. Nucl. Chem., 301, 277 (2014).

29. D. X. Liu, J. Wang, K. Pan, J. Qiu, M. Canova, L. R. Cao, and A. C. Co, Angew. Chemie - Int. Ed., 53, 9498 (2014).

30. X. Zhang, T. W. Verhallen, F. Labohm, and M. Wagemaker, Adv. Energy Mater. (2015), 1500498.

31. K. Schroder, J. Alvarado, T. A. Yersak, J. Li, N. Dudney, L. J. Webb, Y. S. Meng, and K. J. Stevenson, Chem. Mater, 27, 5531 (2015)

32. C. Xu, F. Lindgren, B. Philippe, M. Gorgoi, F. Björefors, K. Edström, and T. Gustafsson, Chem. Mater., 27, 2591 (2015).

33. M. Trunk, M. Wetjen, L. Werner, R. Gernhäuser, B. Märkisch, Z. Révay, H. A. Gasteiger, and R. Gilles (2018), submitted.

34. V. L. Chevrier, L. Liu, D. B. Le, J. Lund, B. Molla, K. Reimer, L. J. Krause, L. D. Jensen, E. Figgemeier, and K. W. Eberman, J. Electrochem. Soc., 161(5), A783 (2014).

35. Z. Révay, P. Kudějová, K. Kleszcz, S. Söllradl, and C. Genreith, Nucl. Instruments Methods Phys. Res. Sect. A, 799, 114 (2015).

36. T. Yoon, C. C. Nguyen, D. M. Seo, and B. L. Lucht, J. Electrochem. Soc., 162(12), A2325 (2015).

37. J. F. Ziegler, M. D. Ziegler, and J. P. Biersack, Nucl. Instruments Methods Phys. Res. Sect. $B, \mathbf{2 6 8}, 1818(2010)$

38. J. F. Ziegler, G. W. Cole, and J. E. E. Baglin, J. Appl. Phys., 43(9), 3809 (1972).

39. D. J. Skyrme, Nucl. Instruments Methods, 57, 61 (1967).

40. P.-K. Lee, Y. Li, and D. Y. W. Yu, J. Electrochem. Soc., 164(1), A6206 (2017).

41. Y. He, R. G. Downing, and H. Wang, J. Power Sources, 287, 226 (2015).

42. L. J. Krause, V. L. Chevrier, L. D. Jensen, and T. Brandt, J. Electrochem. Soc., 164(12), A2527 (2017) 